\title{
An Evaluation of the Financial Cost-Benefit Analysis and Acbr of Obesity Treatment in the Bamenda Municipality
}

\author{
Kinga Bertila Mayin ${ }^{1}$, Sundjo Fabien², Nfor Omarine Nlinwe ${ }^{3}$, Njimanted Godfrey Forgha ${ }^{4}$, * \\ ${ }^{1}$ Department of Health Economics and Policy Management, Faculty of Business and Management Sciences, Catholic University of \\ Cameroon (CATUC) Bamenda, Bamenda, Cameroon \\ ${ }^{2}$ Department of Economics, Higher Teacher Training College, University of Bamenda, Bamenda, Cameroon \\ ${ }^{3}$ Department of Medical Laboratory Science, Faculty of Health Sciences, The University of Bamenda, Bamenda, Cameroon \\ ${ }^{4}$ Department of Management Sciences, Higher Institute of Commerce and Managementigher Institute of Commence and Management, \\ University of Bamenda, Bamenda, Cameroon
}

\section{Email address:}

bertsking@yahoo.com (K. B. Mayin), sundjofabien@rocketmail.com (S. Fabien), omarinenlinwe@yahoo.ca (N. O. Nlinwe),

unicaub@yahoo.com (N. G. Forgha)

${ }^{*}$ Corresponding author

\section{To cite this article:}

Kinga Bertila Mayin, Sundjo Fabien, Nfor Omarine Nlinwe, Njimanted Godfrey Forgha. An Evaluation of the Financial Cost-Benefit Analysis and Acbr of Obesity Treatment in the Bamenda Municipality. Central African Journal of Public Health.

Vol. 6, No. 4, 2020, pp. 180-191. doi: 10.11648/j.cajph.20200604.11

Received: April 21, 2020; Accepted: May 11, 2020; Published: May 28, 2020

\begin{abstract}
According to the WHO report of 2014, 5 people die every minute and 7,671 persons die each day from obesity related complications in the world [36]. Overweight and obesity are the fifth leading risks for global deaths. In June 2013, the American Medical Association recognized obesity as an epidemic. In Cameroon, the prevalence in 2014 stood at $9.6 \%$, second highest in CEMAC after Gabon 15\% (WHO 2014). Following this background, the main objective of this paper is to assess the financial cost and benefits and the Average Cost-Benefit Ratio (ACBR) of obesity treatment in the Bamenda Municipality. Specifically, this paper compares the cost and benefit of obesity treatment and calculates the average cost-benefit Ratio of obesity treatment. To ascertain this objective, use is made of exploratory, descriptive and primary and secondary data is employed. Primary data was collected from 100 hypertensive and 100 diabetes individuals age 20 and above from the Bamenda general hospital. Used was also made of information collected during a six month participatory observation at 2 separate gyms. Secondary data was gotten from WHO and National Cancer Institute. Results show a yearly cost of obesity treatment of 492,000 and a yearly benefit of obesity treatment of 6,677,250 giving a net benefit of 6,185,250fcfa for treating obesity annually. The results also give an ACBR of 0.07 indicating a weight loss project is worthwhile. From the findings we recommend a massive sensitization on the consequences of obesity and the creation of an obesity rehabilitation centre for those who lack motivation and discipline needed to treat obesity.
\end{abstract}

Keywords: Diabetes, Hypertension, Cancer, CVD and BMI

\section{Introduction}

Recently, obesity has been found to be a major risk factor to many non communicable diseases leading to increase health care expenditures and reduction in life expectancy in many countries [36]. Figures are however higher for developed countries like USA and other developed countries. The rise in overweight and obesity is dramatic in Italy, the worse in Europe with a prevalence of up to $36 \%$. [37]. The high rate of obesity in these developed countries like the USA has also been matched by many studies with high rate of medical expenditures. For example, the medical care costs of obesity in the United States in 2008 were estimated to be $\$ 147$ billion. The annual nationwide productive costs of obesity-related absenteeism ranged between $\$ 3.38$ billion (\$79 per obese individual) and $\$ 6.38$ billion ( $\$ 132$ per obese individual) (National Health and Nutrition Examination Surveys, 2008). In the Fast Facts on Economic Costs of 
Obesity [5], healthcare costs for obesity was one of the biggest causes of chronic diseases in the United States. It was estimated at approximately $\$ 147$ billion to $\$ 210$ billion yearly. They also linked obesity to indirect costs like job absenteeism, costing approximately $\$ 4.3$ billion annually and with lower productivity while at work, costing employers $\$ 506$ per obese worker per year. Colditz (2012) cited in [37] looked at the direct and indirect costs in the U.S. of six common obesity-related conditions - type 2 diabetes, high blood pressure, cardiovascular disease, gallbladder disease, colon cancer, and postmenopausal breast cancer-and determined what percentage of those costs were due to obesity. They estimated that in 1986, obesity was responsible for 5.5 percent of the direct and indirect costs associated with these common medical conditions, or about $\$ 39$ billion. Research investigating the economic cost of obesity in Canada and abroad observed that it results to significant cost to the society. Such costs are related to absenteeism, disability and other productivity losses that obesity engenders and are at least as high as costs related to health care [1]. In [39] the expected benefit per enrollment in a weight loss program for treating obesity was calculated at 690 dollars. The associated cost of the program was 202 dollars per enrollment. The average benefit outweighed the cost by an overwhelming ratio of over three-to-one.

In Africa, though obesity figures show comparatively lower rates compared to those of developed countries, some Africa countries like South Africa and Egypt unexpectedly scored $27.7 \%$ and $26.6 \%$ respectively indicating high prevalent rate of adult obesity as of 2012 [35]. The rate of $31.3 \%$ recorded in 2014 by South Africa is a clear indication that obesity rate is on the rise and hence a source for concern at the African level. For other African countries, the adult prevalent rate of obesity for 2014 stood at $16.8 \%$ for Namibia 15.8 for Gabon 10.9 for Ghana, 9.7\% for Nigeria and $8.3 \%$ for Senegal following WHO 2015 report. The average cost for treatment of obesity and obesity related diseases SubSaharan Africa excluding South Africa stood at US\$ 51 in 2006. This is in line with countries such as Senegal and Nigeria [35].

In Cameroon, though obesity rate is far lower than that found in other African countries and Europe, its figures are still higher than that of most CEMAC countries. In 2003, a large survey of adults aged equalor greater than 15 years in four main Cameroonian towns (Yaoundé, Douala, Garoua and Bamenda), revealed that more than $25 \%$ of urban men and almost half of urban women were either overweight or obese, with $6.5 \%$ of men and $19.5 \%$ of women being obese (Justin and Andre, 2011). Cameroon with an obesity prevalence of $9.6 \%$ (2014) spends up to US\$61 per person on health for obesity and other related health problems [37]. The above high cost of treatment is due to the fatal health consequences like diabetes, hypertension and cancer, which results to health care expenditure and great economic burden to the society.: According to Obesity Facts \& Figures [36]. "Overweight and obesity, as well as their related non communicable diseases, are largely preventable. Supportive environments and communities are fundamental in shaping people's choices, making the healthier choice of foods and regular physical activity the easiest choice (accessible, available and affordable), and therefore preventing obesity. At the individual level, people can: limit energy intake from total fats and sugars; increase consumption of fruit and vegetables, as well as legumes, whole grains and nuts; Engage in regular physical activity (60 minutes a day for children and 150 minutes per week for adults)". According to [37] $44 \%$ of diabetes, $35.5 \%$ of hypertension, $24 \%$ of cancer and $60 \%$ of cardiovascular burden has been attributed to obesity.

Obesity has remained an age old problem to health improvement in Cameroon and the Bamenda Municipality in particular. According to Cameroon Burden of diabetes project (2004), obesity prevalence in Bamenda is 33.61 but had reduce to $23.33 \%$ [3]. It is worth noting that these figures are far above the $9.9 \%$ average of Cameroon thus indicating the existence of obesity problem in the Bamenda Municipality. This high prevalence is caused by little or no clear government policy to handle obesity problems directly [33]. With regards to Cameroon, the prevalence of obesity stood at 18.67 for Biyam-Assi, 11.09 for Cite de la Palmiers, 23.33\% for Bamenda, and 10.01\%, Garoua respectively [33]. Indeed Bamenda has the highest percentage of obesity prevalence. Notably, studies addressing the consequences of obesity are scarce and little is known on the cost-benefit analysis and ACBR QALY in the Bamenda Municipality. Thus comprehensively this work then intends to add on existing literature by addressing the issue of obesity treatment in the Bamenda Municipality.

High prevalence of obesity worsens individuals' health. However, sufficient progress has been made in health since the development of the food and nutrition policy in 2006 [33]; the Alma Ata Declaration of 1978 which propagated "Health for All" by the year 2000 and the Ouagadougou Declaration of 2008, which reaffirmed the principles of the Declaration of Alma-Ata of September 1978 [24]; the millennium development goal and then the Sustainable development goal [20].

The growth and employment strategy paper 2010/2020 (Growth and Employment strategy, 2010) also reiterated the above objectives of the MDG now the Sustainable Development Goal (SDG) to promote health for all by 2020 [30]. Health sector strategy paper 2001-2015 saw obesity, hypertension and diabetes as a result of physical inactivity and poor eating habits with much fat, salt and sugar [10]. In 2012, World Health Organization took as part of its commitment to provide technical advice to Member States (which Cameroon is one of them) on implementing the Global Strategy on Diet, Physical Activity and Health [35]. The vision 2035 also aims at providing better health services by 2035 to all Cameroonians. Despite the progress made by health policies, significant gap still remain for Cameroon to achieve these obesity target especially that of curbing non communicable disease which has obesity as a major risk factor. In addition, it has been observed that the citizen of the 
Bamenda Municipality view obesity as a sign of good living. Some attempts made to solve this problem of high prevalence of obesity in Bamenda at the individual and general level has met with mentality and motivation problems, there is therefore an urgent need to address the consequences of obesity and provide a solution that will take care of mentality and motivation problem in the Bamenda Municipality.

This work has as research question: what is the cost, benefit and ACBR of obesity treatment in the Bamenda Municipality? From the above problem, the research questions aimed at achieving the following objectives: The main objective is to evaluate the financial cost-benefits analysis and the Average Cost-Benefit Ratio (ACBR) of obesity treatment in the Bamenda Municipality. Specifically, this paper compares the cost and benefit of obesity treatment and calculates the average cost-benefit Ratio of obesity treatment. The rest of this paper presents: section two dueling on the literature review; section three focusing on the methodology while section four highlighting issues related to the findings and interpretation and finally section five which concludes and makes present the policy implication and recommendations from the findings.

\section{Concepts and Literature Review}

This section defines major concepts and presents literature on other findings on the cost-benefit analysis of obesity treatment. Obesity is defined as an excessive amount of body fat [31] A study on the measures of fatness and obesity in social science research by Burkhauser, and Cawley, [2] noted that all research related to obesity studies uses a person's body mass index (BMI) to quantify obesity. BMI indicates weight in kilograms divided by height in meters squared. If an individual's BMI is greater than 25 but less than 30 , he or she can be classified as overweight. BMI provides the most useful population-level measure of overweight and obesity as it is the same for both sexes and for all ages of adults. Yates and Murphy [39] defined the cost-benefit analysis as the weighing up of the costs and benefits of the different strategies. In terms of obesity, it is therefore providing an estimate of the potential cost of obesity compared with the expected benefit per enrollment in a weight loss program in monetary terms. Cost-benefit analysis is a logical way of making decisions based upon the probable outcomes of various courses of action.

Theoretically, this work uses the health care demand theory as its foundation in understanding and formulation of the obesity model. Grossman, [8] used the theory of human capital to explain the demand for health and health care. According to this human capital theory, individuals invest in themselves through education, training, and health to increase their earnings. This model states that the demand for health care is a derived demand from the demand for health. Health care is demanded as a means for consumers to achieve a larger stock of "health capital." The demand for health is unlike most other goods because individuals allocate resources in order to consume and produce health. Applying this theory to this work, the demand for sport or diet to get a healthy weight is a derived demand for good health void for diseases (like diabetes, hypertension cardiovascular heat diseases and cancer) which have obesity as their risk factors. In Grossman's model, the optimal level of investment in health occurs where the marginal cost of health capital is equal to the marginal benefit. In the obesity case, it therefore implies that, people will only watch their weight if the benefit exceeds the cost of doing so. This will be calculated using the cost-benefit analysis. The results of the cost benefit analysis will tell if it is worthwhile investing resources and time on weigh watching. With the passing of time, health depreciates at some rate $\delta$. The interest rate faced by the consumer is denoted by $r$. The marginal benefit of health capital is the rate of return from this capital in both market and non-market sectors. That is, the benefit from obesity treatment will be the benefit gotten from satisfaction from your new weight and the health care costs saved as a result of treatment.

A number of studies have attempted to compare the cost of obesity treatment to its benefits as follows: Johannesson and Fagerberg, [13] carried out comparison of diet and drug treatment in cost-effectiveness simulations with different assumptions as to the effect upon coronary heart disease risk from the changes in diastolic blood pressure and cholesterol, both total and high-density lipoprotein. A cost-benefit analysis was also performed, calculated as willingness to pay for treatment, as assessed by questionnaire, minus total cost. Dietary treatment was based upon weight reduction and sodium restriction. Drug treatment used a stepped-care approach, with atenolol as the drug of first choice. Their study concluded that non-pharmacological treatment seemed to be less cost-effective than drug treatment for obese men with mild hypertension.

Surg, [32] also did a cost-benefit analysis for the treatment of severe obesity. He set up a formal cost effective analysis (CEAs) for medical and surgical obesity treatments, and lists published reports that demonstrate the effectiveness of surgical obesity treatments. His findings established a level of effectiveness of surgery treatment far surpassing many other forms of medical therapy. Colditz (2012) cited in [37] looked at the direct and indirect costs in the U.S. of six common obesity-related conditions-type 2 diabetes, high blood pressure, cardiovascular disease, gallbladder disease, colon cancer, and postmenopausal breast cancer-and determined what percentage of those costs were due to obesity. He estimated that in 1986, obesity was responsible for 5.5 percent of the direct and indirect costs associated with these common medical conditions, or about \$39 billion.

Yates and Murphy [39] carried out a cost-benefit analysis of weight management strategies. They assessed and compared alternative programs for reducing the current prevalence of obesity. This involved weighing up the costs and benefits of the different strategies. So, in addition to providing an updated estimate of the potential cost of obesity in Australia, their paper used a weight management program to illustrate the methodology used in assessing alternative 
intervention programs. The expected benefit per enrollment in a weight loss program was calculated at 690 dollars. The associated cost of the program was 202 dollars per enrollment. The average benefit outweighed the cost by an overwhelming ratio of over three-to-one. Their findings indicate that weight loss program more beneficial than their cost in monetary terms. Lindeboom et al., [18] also studied the effect of obesity on employment, using rich data from the British National Child Development Study (NCDS). Their correlation results showed a significant negative association between obesity and employment even after controlling for a rich set of demographic, socioeconomic, environmental and behavioral variables.

Finkelstein et al. [6] carried out an estimate of the lifetime medical costs of an obese child. Their results showed an incremental lifetime direct medical cost from the perspective of a 10-year-old obese child relative to a 10-year-old normal weight child ranges from $\$ 12660$ to $\$ 19630$, when weight gain through adulthood among normal weight children is accounted for and from $\$ 16310$ to $\$ 39080$, when this adjustment is not made. According to National institute of public health Quebec [22], Obesity and overweight are risk factors linked to the appearance of a number of chronic diseases such as diabetes and cardiovascular disease. However, obesity also has an economic impact. National institute of public health Quebec [22] has quantified the economic burden of obesity in Canada and abroad observed that the problem engenders significant costs for society. Such costs are not confined to those stemming from broader recourse to health services. Costs related to absenteeism, disability and other productivity losses that obesity engenders are at least as high as costs related to health care [22]. Gatineau [7] studied the cost- benefit analysis of obesity and also showed that being overweight or obese is the main modifiable risk factor for type 2 diabetes. People with severe obesity were at greater risk of type 2 diabetes than obese people with a lower BMI. Inequalities deprivation was closely linked to the risk of both obesity and type 2 diabetes. Prevalence of type 2 diabetes was $40 \%$ more common among people in the most deprived quintile compared with those in the least deprived quintile [7].

Obesity Consequences

Obesity and Type 2 Diabetes

In type 2 diabetes, the body's cells do not use insulin properly. At first, the body reacts by making more insulin. Over time, however, the body cannot make enough insulin to control its blood sugar level leading to a medical condition known as diabetes. Both increased insulin secretion and insulin resistance result from obesity [18]. It is worthy of note that obesity develops in more than $50 \%$ of nonhuman primates as they age [17]. Nearly half of these obese animals subsequently develop diabetes [17].

Obesity and High Blood Pressure

According to Lewis et al. [17] individuals with hypertension are currently defined as untreated SBP $\geq 140$ $\mathrm{mm} \mathrm{Hg}$ or DBP $\geq 90 \mathrm{~mm} \mathrm{Hg}$. When one's blood pressure is high, this Blood pressure is the force of blood pushing against the walls of the arteries as the heart pumps blood. If this pressure rises and stays high over time, it can damage the body in many ways. Individual's chances of having high blood pressure are greater if they are overweight or obese [17]. In light of the worldwide epidemic of obesity, and in recognition of hypertension as a major factor in the cardiovascular morbidity and mortality associated with obesity, the Obesity Society and the American Society of Hypertension (1980) agreed to jointly sponsor a position paper on obesity-related hypertension. Given the frequent concurrence of obesity and hypertension, it is no coincidence that as the rate of obesity continues to rise, so too does the rate of hypertension [17].

Obesity and Cardiovascular Disease

According to Eckel, [4] until recently the relation between obesity and coronary heart disease was viewed as indirect, that is, through covariates related to both obesity and coronary heart disease risk, including hypertension; dyslipidemia, particularly reductions incholesterol; and impaired glucose tolerance or non-insulin-dependent diabetes mellitus. Long-term longitudinal studies by Eckel, [4], however, indicate that obesity as such not only relates to but independently predicts coronary atherosclerosis. Hendrick, [11] also found out that obesity is a risk factor for fatal heart attacks even for people who do not have the conditions normally associated with cardiovascular disease, such as diabetes and high blood pressure. According to Konnopka, Bödemann and König, [16], obesity is among the leading causes of elevated cardiovascular disease (CVD), mortality and morbidity. In his study, the associations between the increase in body mass index (BMI) and the increase rates of CVD and high blood pressure (HBP).

Obesity and Cancer

A study by the National Cancer Institute (NCI), [21] in USA on cancer and obesity risk, established the association between cancer and obesity as seen in the paragraphs. Obesity is associated with increased risks of the following cancer types, and possibly others as well: Esophagus, Pancreas, Colon and rectum, Breast (after menopause), Endometrium (lining of the uterus), Kidney, Thyroid, Gallbladder cancer. One study, using NCI Surveillance, Epidemiology, and End Results (SEER) data, estimated that in 2007 in the United States, about 34,000 new cases of cancer in men ( 4 percent) and 50,500 in women ( 7 percent) were due to obesity. The percentage of cases attributed to obesity varied widely for different cancer types but was as high as 40 percent for some cancers, particularly endometrial cancer and esophageal adenocarcinoma.

Obesity Cost

According to Obesity Facts and Figures of [36]. "Overweight and obesity, as well as their related non communicable diseases, are largely preventable. Supportive environments and communities are fundamental in shaping people's choices, making the healthier choice of foods and regular physical activity the easiest choice (accessible, available and affordable), and therefore preventing obesity. At the individual level, people can: limit energy intake from 
total fats and sugars; increase consumption of fruit and vegetables, as well as legumes, whole grains and nuts; Engage in regular physical activity (60 minutes a day for children and 150 minutes per week for adults)". Statistics on Obesity, Physical Activity and Diet: England, [26] says that "the current government food based recommendations are that everyone should eat plenty of fruit and vegetables (at least 5 of a variety each day), plenty of potatoes, bread, rice and other starchyfoods, some milk and dairy foods, meat, fish, eggs, beans and other non-dairy sources of protein. Foods and drinks high in salt, fat and sugar should be consumed infrequently and in small amounts. The Active People Survey, published by Sport England (2013), provides information on participation in sport and the measurements for the local area estimates of adults playing sport for at least 30 minutes a week. Looking at the above recommendation from WHO and England report on reducing obesity, it is observe that the calculation the cost of obesityis directed towards the cost of fruits, vegetables and physical activity (gym). The cost of whole grains is left out since in the Bamenda Municipality, most of our food contains whole grains.

The difference between this work and the work of Yates and Murphy [39] and a host of other literature review above is that, while most of them used the cost of a specific weight management program common in western world, this work however due to lack of such programs in the Bamenda Municipality, uses a combination of diet and gym to represent such management program in our context. In addition, the other works have all been carried out in developed countries like in Australia with and little or none in Cameroon talk less of the Bamenda Municipality. More so, most of the literature used different economic cost methods like cost of disease treatment [6] and the cost-effective analysis [32] to capture cost-benefit analysis. Some of the above works in calculating the benefit of obesity treatment have also considered both direct medical cost and indirect cost stemming from lost in productivity and employment [21]. However for simplicity and due to the difficulties of estimating the cost of absenteeism, this work focus only on the direct health cost of obesity in the calculation of the benefit of obesity treatment. The direct medical cost use in this work is calculated from the mean cost of treating obesity related diseases (diabetes, hypertension, cancer and cardiovascular diseases). In addition, most of these works [36] were carried out decade ago thus warranting a recent studies like this in the Bamenda Municipality so as to be able to draw relevant policy recommendation on the cost benefit analysis and its ACBR in the Bamenda municipality.

\section{Methodology}

The time scope of this work was limited to data collected from both primary and secondary source from 2017 to 2018 . Looking at the definitional scope, the study adopts the definition of the W. H. O. [35]. They defined obesity as abnormal or excessive fat accumulation that may impair health; have important consequences for morbidity, disability and quality of life; entail higher risk of developing type 2 diabetes, hypertension, cardiovascular diseases, several common forms of cancer, osteoarthritis and other health problems; and are of serious public health challenges. The area of study is the Bamenda Municipality of the NWR of Cameroon. Bamenda, also known as Abakwa, sprawling over the north-western plateau of Cameroon, is the capital city of the North West Region found in the western highlands of Cameroon. The North West Region has a population estimate of about 1.8 million, distributed within seven administrative Divisions thus: Boyo, Bui, Donga-Mantung, Menchum, Mezam, Momo and Ngoketunjia. Bamenda the chief town of Mezam division is the third-ranked city in Cameroon and is situated $366 \mathrm{~km}$ north-west of the administrative capital of Cameroon, Yaounde, and about $450 \mathrm{~km}$ of Cameroon's economic capital, Douala. The Bamenda Municipality has a population of about 800,000 people [21]. It is made up of three subdivisions promulgated by the Presidential Decree of 17th January 2008 which dissolved its urban status and created Bamenda I, Bamenda II, Bamenda III Councils and the Bamenda City Council. This town runs through 3 villages Bamendankwe, Mankon and Nkwen, which make up the Bamenda I, Bamenda II and Bamenda III respectively. The population of Bamenda I, II and III stood at 28,468, 184,277 and 110,253 respectively [21].

This study uses both the exploratory, causal and the descriptive research design. The data was presented using tables and charts. Used was made of primary (observation and questionnaires) and secondary data in this research. Observation was done by participating for three months each in two separate gyms (LANGO in 2017 and MACO in 2018) and CMA hospital. For the calculation of cost-benefit analysis, data was collected on the cost of going to the gym, using participatory observations. To get the cost of treatment for diabetes, hypertension, we collected data from the Bamenda General Hospital, with the authorization of the regional delegate of public health for the North West region (NWR). However, the cost of treatment of cancer and cardiovascular diseases were difficult to get since these diseases have different complications at different levels and most of their patients end up in other specialized centre like Yaoundé and Douala. Cancer in particular had different types with varied treatment cost. This research therefore resorted to the findings from experts and credible and specialized institutions like the WHO and the National cancer control committee to get the mean cost of treatment for these two diseases.

Cost-Benefit Analysis of Obesity

Total cost of obesity treatment (TC) - Total benefits from obesity treatment (TB).

If $\mathrm{TC}>\mathrm{TB}$, then we have a negative net benefit, implying that obesity treatment is not Beneficial.

If $\mathrm{TC}<\mathrm{TB}$, then we have a positive net benefit, implying that Obesity treatment is Beneficial.

If $\mathrm{TC}=\mathrm{TB}$, then we have 0 net benefit, implying, Obesity treatment is not necessary. 
Cost of obesity treatment is how much it cost an obese patient to move from obese to a normal weight.

Here benefit will be calculated in terms of the money individuals would use in treating obesity related complications (diabetes, hypertension cardiovascular diseases and cancer).

Table 1. Description of variables used in the estimation cost-benefit analysis.

\begin{tabular}{lll}
\hline Variable & Meaning & Description \\
\hline TC & Treatment Cost & The cost of treatment was attributed to the cost of sports and diet used for obesity treatment. \\
TB & Treatment Benefit & $\begin{array}{l}\text { Captured by the cost averted in treating obesity related illnesses. In this work, we took into consideration } \\
\text { diabetes, hypertension, cardiovascular diseases and cancer. }\end{array}$ \\
\hline
\end{tabular}

Computed by authors

Justification for Inclusion of Variables in the Model

This section justifies the reason for the inclusion of the variables and components when calculating cost-benefit analysis and the ACBR

The Benefit of Obesity Treatment

The benefit of obesity treatment was calculated as the medical expenditures that the individuals will avoid if they were not obese. This cost is usually calculated as the cost incurred from obesity related illnesses. Thus to calculate the benefit of obesity treatment we calculated the cost of treating common diseases which have as risk factor obesity. For simplicity, though more than 10 diseases (like cancer, arthritis, stroke and cardiovascular diseases) have obesity as a risk factor, only four diseases which have high percentage of their risk factors attributed to obesity was considered. The diseases considered in this work are Diabetes, where $44 \%$ of the diabetes burden is attributed to obesity [37]; Hypertension, $35.5 \%$ of obese adults had hypertension [37]. Cancer, where $24 \%$ cancer burden is attributed to obesity [37] and 60\%cardiovascular disease [11]. An average of cost of treatment of cancer was gotten from the work of from Prince et al.[27, 23, 19] which reviewed it cost 1953000 to treat a cancer patient a year and 162750 frs for their monthly treatment in Cameroon. According to a WHO sponsored study carried out by Jingi et al. [12] one month of combination treatment for coronary heart disease costs at least 38,145 to treat patients living with cardiovascular diseases at the minor stage.

The Cost of Obesity Treatment

This section is concerned with how much obesity treatment will cost an individual. To know the cost of obesity treatment for an individual, one needs to know what the obesity treatment will be. This work adopts the treatment option of WHO [36] which specifies people limit energy intake from total fats and sugars; increase consumption of fruit and vegetables, as well as legumes, whole grains and nuts and engage in regular physical activity (60 minutes a day for children and 150 minutes per week for adults). Findings from participatory observation show that many obese individuals who registered in the gym succeeded to reduce their weight just by dieting and physical exercise. Participants in a 1 month highest weight losers contest organized during our observation succeeded to lose between 4 to 10 kilogram in a month irrespective of their genes and age. Participants who depended on sports only lose smaller weights compared to those who combined exercise and diet. Some participants also commented that diet alone could make them lose weight; however, they confessed that when combined with physical exercise, the weight loss process becomes more rapid. Other set of individuals who were regular in the gyms but lose very little or no weight, confess to have been eating too much. From the above observation, this work, like the WHO recommend a combination of diet with fruits and vegetables and sports for effective and rapid weight lost. In addition, to maintaining a healthy weight, dieting must become a lifestyle.

Use was made of the summary statistics to presents the data collected from the field. The chi-square analysis was used to validate the hypothesis and make valid policy recommendations. Assessingthe cost-benefit analysis and ACBR, we used the cost benefit analysis technique as used by [39] which is a technique capable of comparing the cost of an investment like investing on weight loss and the expected benefits in monetary term. This methodology is most suitable here because unlike the other costing techniques like the cost effective analysis, this is the only technique that calculate the benefit for health investment in monetary terms thus making it not only most comprehensive for many but also comparable with other projects. The Average Cost-Benefit Ratiosis calculated using its standard formulae thus:

$$
\mathrm{ACBR}=\frac{\text { Costinmonetaryterm }}{\text { benefitmonetaryterm }}
$$

\section{Results and Discussion}

Presentation of Summary Statistics

Table 2. Summary Statistics age and weight at death and cost of treatment of diabetes and hypertension.

\begin{tabular}{llllll}
\hline & & Age at death & Weight at death & $\begin{array}{l}\text { Mean monthly cost of } \\
\text { diabetes treatment }\end{array}$ & $\begin{array}{l}\text { Mean monthly cost of } \\
\text { hypertension treatment }\end{array}$ \\
\hline $\mathrm{N}$ & Valid & 149 & 149 & 100 & 100 \\
\hline
\end{tabular}




\begin{tabular}{lllll}
\hline & Age at death & Weight at death & $\begin{array}{l}\text { Mean monthly cost of } \\
\text { diabetes treatment }\end{array}$ & $\begin{array}{l}\text { Mean monthly cost of } \\
\text { hypertension treatment }\end{array}$ \\
\hline Mean & 59.80 & 69.37 & 9000 & 12680 \\
Std. Deviation & 19.377 & 13.489 & 6060.687 & 15919.142 \\
Range & 82 & 88 & 22000 & 90200 \\
Minimum & 20 & 37 & 3000 & 600 \\
Maximum & 102 & 25000 & 90800 \\
\hline
\end{tabular}

Source: Computed by authorsusing SPSS 17.

Table 2, presents the mean age and weight at death for patients age 20 and above who died in the general hospital in 2018 was 59.8 and 69.37 respectively. It is worth noting that thisworkis more interested in the weight of patients who died from obesity related complication so as to be able to establish a link between obesity and these illnesses. From the table, the mean cost for the treatment of diabetes and hypertension is $9000 \mathrm{frs}$ and $12680 \mathrm{frs}$ respectively.

Table 3. Causes of Death in the Bamenda Municipality.

\begin{tabular}{llllll}
\hline & Frequency & Percent & Valid Percent & Cumulative Percent \\
\hline \multirow{4}{*}{ Valid } & 23 & 15.3 & 15.3 & 15.3 \\
& CANCER & 23 & 15.3 & 15.3 & 30.7 \\
& CARDIOVASCULAR & 2 & 1.3 & 1.3 & 32.0 \\
& DIABETES & 7 & 4.7 & 4.7 & 40.0 \\
& HYPERTEN & 95 & 63.3 & 63.3 & 100.0 \\
& OTHER & 150 & 100.0 & 100.0 & \\
\hline
\end{tabular}

Computed by authors using SPSS 17.

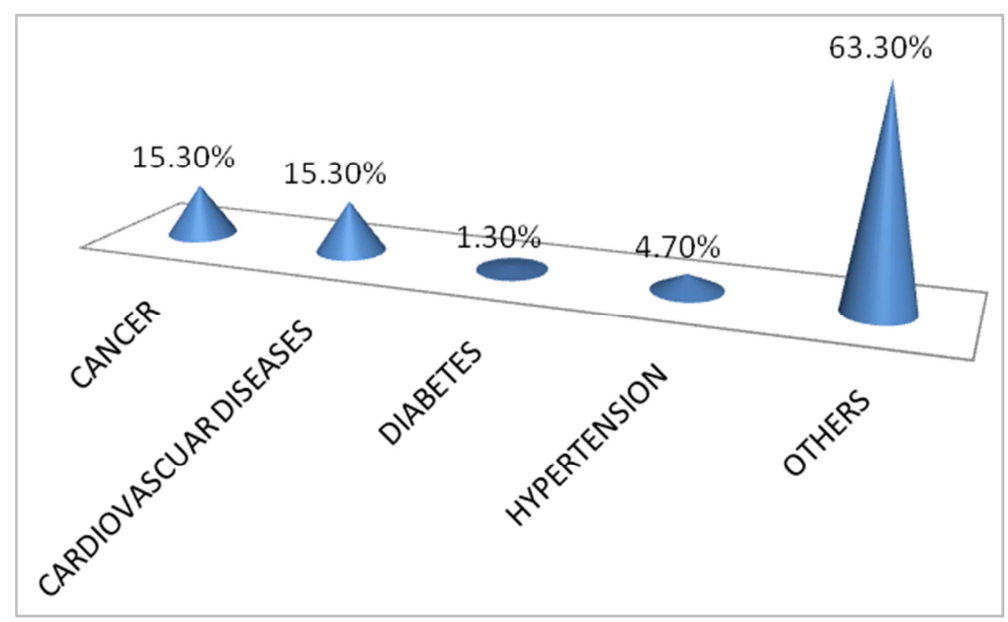

Source: Computer by authors using SPSS 17.

Figure 1. Causes of Death.

Looking at figure 1 , it can be notice that among the obesity related causes of death, cancer and cardiovascular diseases were the highest. Up to $30.6 \%$ percent of those who died in the Bamenda municipality died from either cancer or cardiovascular diseases. This gives us up to $36.7 \%$ (diabetes and hypertension inclusive) of deaths related to obesity. From the statistics, contrary to peoples prevention of obesity due to their fright of dying from diabetes and hypertension, more people now die from cancer and cardiovascular diseases which research has proven to be directly and strongly linked to obesity.

Table 4. Chi-Square Result for Causes of Death Obesity, Sex and Age at Death.

\begin{tabular}{|c|c|c|c|c|c|c|}
\hline \multirow{2}{*}{ Variable } & \multicolumn{6}{|c|}{ Cause of death } \\
\hline & Cancer & Cardiovascular & Diabetes & Hypertension & Others & Total \\
\hline \multicolumn{7}{|l|}{ Obesity } \\
\hline Non Obese & $17(11.3 \%)$ & $11(7.3 \%)$ & $1(0.7 \%)$ & $5(3.3 \%)$ & $81(54.0 \%)$ & $115(76.7 \%)$ \\
\hline Obese & $6(4.0 \%)$ & $12(8.0 \%)$ & $1(0.7 \%)$ & $2(1.3 \%)$ & $14(9.3 \%)$ & $35(23.3 \%)$ \\
\hline ProbX ${ }^{2}$ & & & & & & 0.004 \\
\hline \multicolumn{7}{|l|}{ Gender } \\
\hline Female & $2(1.3 \%)$ & $8(5.3 \%)$ & $1(0.7 \%)$ & $2(1.3 \%)$ & $27(18 \%)$ & $40(26.7 \%)$ \\
\hline Male & $21(14.0 \%)$ & $15(10.0 \%)$ & $1(0.7 \%)$ & $6(3.3 \%)$ & $68(45.3 \%)$ & $110(76.3 \%)$ \\
\hline ProbX ${ }^{2}$ & & & & & & 0.259 \\
\hline Age & & & & & & \\
\hline
\end{tabular}




\begin{tabular}{|c|c|c|c|c|c|c|}
\hline \multirow{2}{*}{ Variable } & \multicolumn{6}{|c|}{ Cause of death } \\
\hline & Cancer & Cardiovascular & Diabetes & Hypertension & Others & Total \\
\hline$\leq 49$ & $3(2 \%)$ & $4(2.7 \%)$ & $2(1.4 \%)$ & $3(2 \%)$ & $36(24.0 \%)$ & $48(31.3 \%)$ \\
\hline $50-59$ & $4(2.7 \%)$ & $2(1.3 \%)$ & $0(0.0 \%)$ & $1(0.7 \%)$ & $11(7.3 \%)$ & $18(12 \%)$ \\
\hline $60-69$ & $6(4 \%)$ & $4(2.7 \%)$ & $0(0.0 \%)$ & $0(0.0 \%)$ & $17(11.3 \%)$ & $27(18 \%)$ \\
\hline $70-79$ & $5(3.3 \%)$ & $9(6 \%)$ & $0(0 \%)$ & $1(0.7 \%)$ & $14(9.3 \%)$ & $29(19.3 \%)$ \\
\hline $80-89$ & $5(3.3 \%)$ & $4(2.7 \%)$ & $0(0 \%)$ & $2(1.3 \%)$ & $13(8.7 \%)$ & $24(16 \%)$ \\
\hline$\geq 90$ & $0(0 \%)$ & $0(0 \%)$ & $0(0 \%)$ & $0(0 \%)$ & $4(2.7 \%)$ & $4(2.7 \%)$ \\
\hline ProbX $^{2}$ & & & & & 93.61 & 0.000 \\
\hline
\end{tabular}

Source: Computed by authors using SPSS 17.

Table 4 presents, the chi-square results for causes of death by obesity, gender and age at death. The results show that the causes of death statistically depended on being obese ( $p$ value $=0.004)$ and age $(p$-value $=0.00)$. This means that being obese made more people died from obesity related diseases and that more of the aged died from obesity related diseases.

cancer cardiovascular disease
It also shows that the causes of death was statistically independent of gender ( $\mathrm{p}$-value $=0.26$ ). That is the causes of death did not depend on the gender. The table also provides valid frequencies and percentages for causes of death and its different dependent variables. These results have been represented on figures 2,3 and 4 .

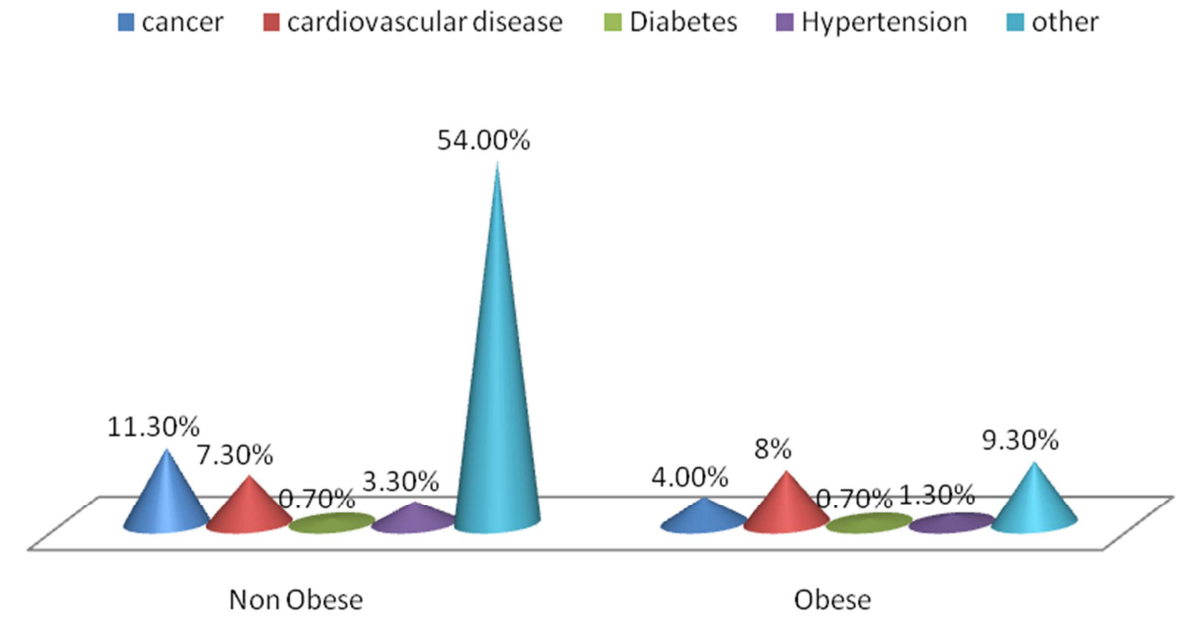

Source: Computer by authors using SPSS 17.

Figure 2. Causes of Disease by Weight.

Diseases

From figure 2, more obese patients died from cardiovascular diseases compared to other diseases. The chi square results of 0.004 also show a statistical significant relationship between being obese and the cause of death in the Bamenda Municipality.

$$
\text { ancer } \square \text { cardiovasculardisease } \square \text { Diabetes } \square \text { Hypertension } \square \text { other }
$$

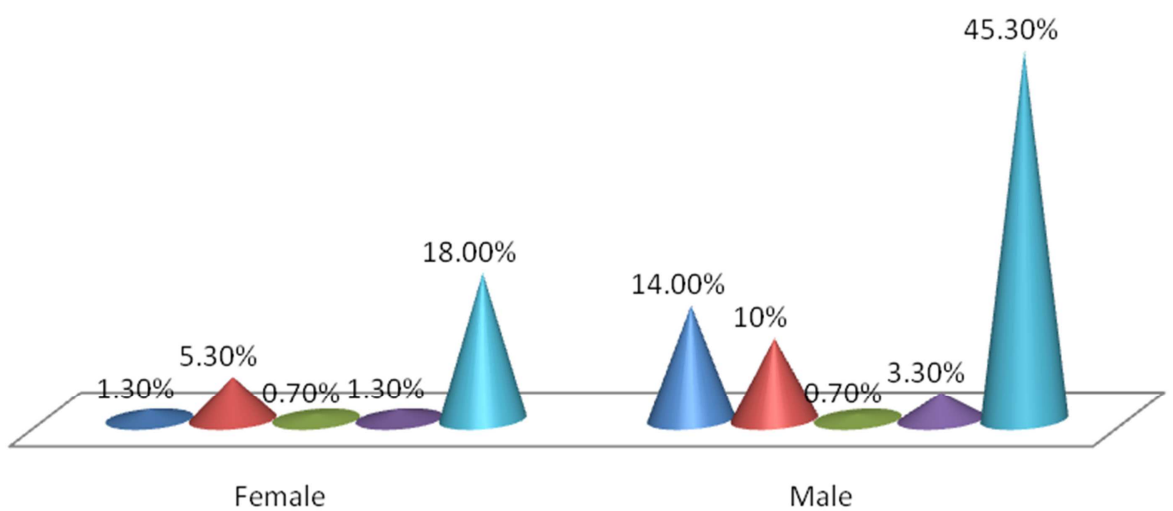

Source: Computer by authors using SPSS 17.

Figure 3. Causes of Death by gender. 
Figure 3 show that, more men died from cancer, cardiovascular diseases, diabetes and hypertension and other diseases compared to women.

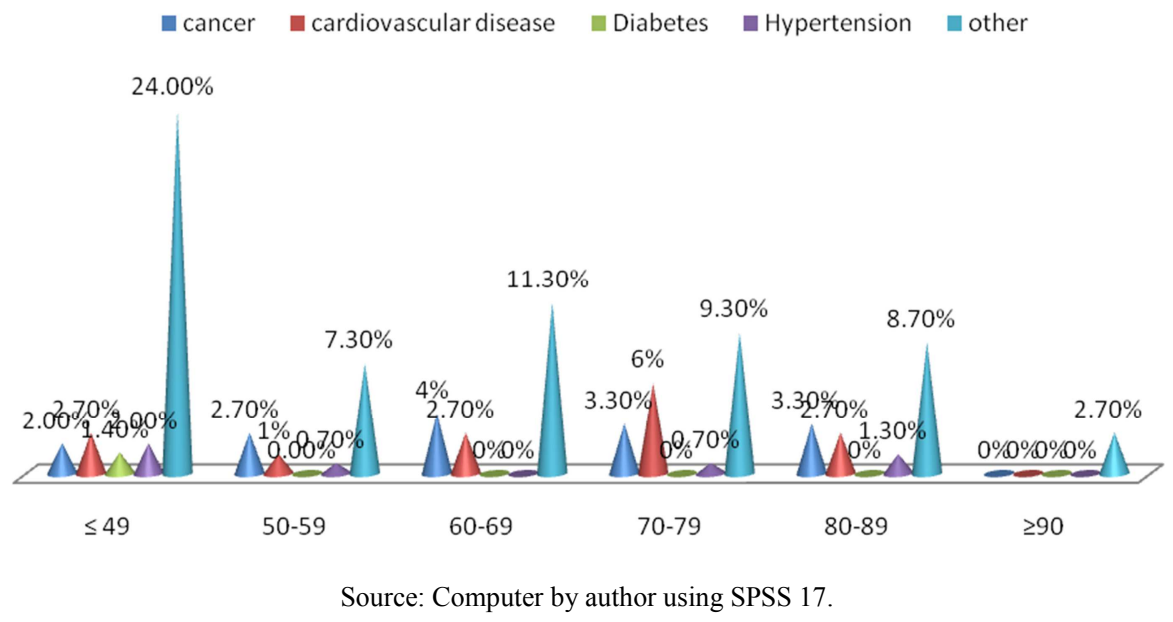

Figure 4. Cause of Death by age group.

In figure 4, at all age groups, more people died from cancer and cardiovascular diseases compared to diabetes and hypertension. The chi square figure $(0.000)$ of this result shows a statistical significant relationship between causes of death and ages at death.

Calculation of Obesity Benefits

The total prevalence of adult obesity in the Bamenda Municipality stood at 23.33 for Bamenda in 2011 (demographic health survey 2011). To get the benefits for the whole of Bamenda Municipality, we shall multiply the cost per person by the prevalence of obesity $23.33 \%$ of the population of the Bamenda Municipality which stood at about 800,000 people (national Census, 2012). (23.33/100 $\times$ 800,000 people $=186640$ people). Thus, the burden of obesity in the Bamenda municipality was calculated on 186640 people in the Bamenda municipality.

Table 5. Calculation of benefit of obesity treatment.

\begin{tabular}{|c|c|c|c|c|c|}
\hline Illness & $\begin{array}{l}\text { obese population } \\
\text { for Bamenda Municipality } \\
\text { (adult obesity rate } \times \text { pop of } \\
\text { Bamenda) }\end{array}$ & $\begin{array}{l}\% \text { of disease } \\
\text { attributed to } \\
\text { obesity }\end{array}$ & $\begin{array}{l}\text { susceptible population } \\
(\text { obese pop } \times \% \text { of } \\
\text { disease attributed to } \\
\text { obesity) }\end{array}$ & $\begin{array}{l}\text { Average } \\
\text { monthly Cost } \\
\text { of treatment } \\
\text { per person }\end{array}$ & $\begin{array}{l}\text { cost of } \\
\text { treatment for } \\
\text { the population } \\
\text { monthly }\end{array}$ \\
\hline Diabetes & 186640 & $44 \%$ & 82121.6 & 9000 & $739,094,400$ \\
\hline Hypertension & 186640 & $33 \%$ & 61591.2 & 12680 & $780,976,416$ \\
\hline Cancer & 186640 & $24 \%$ & 44793.6 & 162750 & $7,290,158,400$ \\
\hline Cardiovascular Disease & 186640 & $60 \%$ & 111984 & 38145 & $4,271,629,680$ \\
\hline Individual monthly Benefit & & 222,575 & & & \\
\hline Community daily benefit & $222,575 * 186640=436,062,000$ & & & & \\
\hline Individual yearlyBenefit & $222,575 * 30$ & & $6,677,250$ & & \\
\hline
\end{tabular}

Source: Computed manually by authors.

From the results presented on table 5 , the average yearly obesity treatment cost is $6,677,250$ for an individual considering that obesity exposes individuals to all four diseases. That is, treating obesity will lead to averting such treatment cost and thus a benefit. This thus implies the average monthly treatment benefit for obesity for an individual is
222575. In addition, from our calculations, we can conveniently say that, the daily benefit for obesity treatment is $436,062,000$ for the whole Bamenda municipality. It can be concluded that treating obesity will benefit an individual yearly by $6,677,250$ and the community by $436,062,000$ a day.

Calculation of the Cost of Obesity Treatment

Table 6. Total Cost of Sliming in a Month.

\begin{tabular}{llll}
\hline Activity & Cost per day (FCFA) & Cost per month (FCFA) & Cost per year (FCFA) \\
\hline Gyms (physical activities) & 167 & $5000 * 12$ & 120,000 \\
Fruits & 500 & $15,500 * 12$ & 186,000 \\
Vegetable & 500 & $15,500 * 12$ & 186,000 \\
Total & 1,167 & 36000 & 492,000 \\
\hline
\end{tabular}

Table 6 , indicates that an obese patient spends $167 \mathrm{fcfa}$ in a gym, $500 \mathrm{cfa}$ on fruits, $500 \mathrm{cfa}$ on vegetables a day. This implies that an obese patient spends 1.167FCFA a day to treat obesity. This gives the daily, monthly and yearly cost of 
treating obesity as 1,167fcfa, 36,000fcfa and 492,000fcfa Cost-Benefit Analysis (Net Benefit) respectively.

Table 7. Calculation of Cost benefit analysis.

\begin{tabular}{llll}
\hline S/N & $\begin{array}{l}\text { Yearly Benefit from obesity } \\
\text { treatment (FCFA) }\end{array}$ & $\begin{array}{l}\text { yearly cost of obesity treatment } \\
\text { (FCFA) }\end{array}$ & $\begin{array}{l}\text { Net benefit (Benefit minus Cost } \\
\text { (FCFA) }\end{array}$ \\
\hline 1 & $6,677,250$ & 492,000 & $6,185,250$ \\
\hline
\end{tabular}

Source: Calculated manually by authors.

From the table 7 , the net benefit is positive $(6,185,250 \mathrm{FCFA})$. This means that it will be beneficial for any obese patient to undertake a sliming program since the benefit (in terms of the cost of treating the illness prevented) is more than the cost. In addition, the 'average cost-benefit ratio'(ACBR) was calculated thus:

$$
\mathrm{ACBR}=\frac{\text { Cost in monetary term }}{\text { benefit in monetary term }}=\frac{492,000}{6,677,250}=0.07
$$

An intervention is worthwhile if the ACBR is less than one, i.e., if $\mathrm{ACBR}<1$. Looking at the results of ACBR of 0.07 , it can be seen that obesity treatment is worthwhile.

Discussion of Results from the Cost-Benefit Analysis

The result of the Cost-Benefit analysis shows that the yearly benefit $(6,677,250 \mathrm{fcfa})$ of obesity treatment surpasses the cost $(492,000 \mathrm{fcfa})$. This gives a net benefit of $6,185,250 \mathrm{fcfa}$ for obesity treatment and an Average CostBenefit Ratio (ACBRs) of 0.07. This finding is in line with the work of Grossman (1972) who stated that if the marginal efficiency of investment just equals the cost of capital, then it is necessary to invest. In this case, if the rate of return on obesity treatment is greater than its cost, then people will be willing to reduce their weights. This means that obesity should be treated only up to the point where: Rate of return of the treatment $=$ Cost of the treatment. In our context, this implies that people should invest in cutting obesity if and only if they will have more benefit than the cost of doing so. From the participatory observation, we observed that not only is it cheaper to lose weight, but it is very possible too. Many people we talked to about obesity, during the writing period, believed their weights were natural and that there is little or nothing one can do to maintain a healthy weight. Many women especially attributed weight to child birth and believed such weight can never be removed. Contrary to popular opinion, all those who participated in a weight loss context in the gym, where we did the participatory observation succeeded to lose $5 \mathrm{~kg}$ on an average monthly just by doing sport and dieting. In addition, irrespective of participants' genetic makeup, the weakest participant succeeded in losing on an average $4 \mathrm{~kg}$ in a month. This thus means that irrespective of whether you have fat genes or not, you can still lose weight if you take dieting and sport seriously. This means that on an average an individual can lose $48 \mathrm{~kg}$ in a year which is enough to treat all types of obesity. This work concluded from the observation that there is no individual in the world who cannot lose weight if he/she wishes to do so. All he/she needs is the right mindset and motivation. With the right mentality, people are able to believe the saying that "obesity is not a sign of good living" and be motivated and determined to exercise and dieting.

\section{Conclusion and Policy Implications}

This paper aimed at assessing the financial cost, benefit and the ACBR of obesity treatment in the Bamenda municipality. In order to do this, data was collected on the cost of treatment obesity related diseases for patients at the Bamenda Municipality. Data was also collected on the cost of treatment of cancer and cardiovascular diseases from secondary sources. To estimate the cost of obesity treatment, data was collected from participatory observation during a six months stay in two separate gyms (LANGO and MACO fitness gyms). To enrich our knowledge on cost of treatments we also enrolled for a one month internship at the finance department at the CMA Nkwen hospital which has a diabetes and hypertension centre. Use was made of both the exploratory, descriptive, Standard formula and causal research design to validate our objective. The results show that the yearly benefit of obesity treatment is $6,677,250 \mathrm{FCFA}$ while the yearly cost for obesity treatment is $492,000 \mathrm{FCFA}$. This gave a net benefit of $6,185,250$ FCFA for treating obesity. An ACBRs of 0.07 was obtained and it was concluded that it is cost benefit to treat obesity. From the findings, we recommend that all obese individuals irrespective of their genetic set up can lose weight therefore should actively engage in weight losing processes. From the findings, we recommend the need to increase fitness exercises, intake of vegetables, fruits and reduce the consumption of sugar, salt, carbohydrate and fats both for obese patients as a treatment measure and non obese individuals as a preventive measure of obesity. Lastly the creation of an obesity rehabilitation centre for those who lack the adequate motivation and discipline to sustain a weight loss program by themselves is recommended.

\section{Acknowledgements}

We would like to express my special appreciation and thanks to Prof Mbacham Wilfred who co-supervised this work. Our sincere appreciation goes to Ass Prof. Dobdinga Cletus, DrSunjo Fabian and DrNuh buy in Hilda Fokum of The University of Bamenda for their tireless effort in editing this Paper. We cannot forget the contributions of the academic and technical staff of the Catholic University of Bamenda. They provided the 
necessary scholarly support that facilitated the success of this programme especially Mr Asah Promisse. We are also indebted Dr Nji Christopher, Miss Lemnui Gilian, Mrs Verla yvone, who helped in the data collection process and to other participants in the survey who willingly shared their precious time to respond to the interview guide and questionnaires instrument.

\section{References}

[1] Blouin, C. (2014) The economic impact of obesity and overweight. Summaries by the Nutrition-Physical ActivityWeight Team, Issue 9.

[2] Burkhauser, RV. and Cawley J. (2008). Beyond BMI: the Value of More Accurate Measures of Fatness and Obesity in Social Science research. Journal of Health Economics.

[3] DHS. (2011). Demographic Health Survey and Multiple Indicators.www.dhsprogram.org.

[4] Eckel, R. H. (1997). A Statement for Healthcare Professionals From the Nutrition Committee. American Heart Association, https://doi.org/10.1161/01. CIR. 96.9.3248 Circulation. 1997; 96: 3248-3250.

[5] Fast Facts of Obesity. (2006). Economic Costs of Obesity on Health Care. A project of the Trust for America Health and the Robert Wood Johnson Foundation.

[6] Finkelstein EA., Trogdon JG. Cohen JW and Dietz W. (2009). Annual Medical Spending Attributable to Obesity. Payer- and Service-specific Estimates. Health Affairs, 28 (5): w822-831.

[7] Gatineau Mary. (2014). Adult obesity and type 2 diabetes. Public Health England 133. PHE publications gateway number: 2014211.

[8] Grossman, M. (1972a). The Concept of Health Capital and the Demand for Health. Journal of Political Economy, 80 (2): 223-255, doi: 10.1086/259880.

[9] Growth and Employment strategy. (2010). Reference Framework for government action over period 2010-2020. Cameroon.sector strategy monetoring metrice.

[10] Health Sector Strategy Paper. (2001). The Health sector strategy paper 2001-2015. Cameroon Report. www. Minsante.cm.

[11] Hendrick, B.. (2011). Obesity Increases Risk of Deadly Heart Attacks. WebMD Archives.

[12] Jingi Ahmadou M, Noubiap, J. J., Nansseu, J. R., Wang, B., Kingue, S., and Kengne. (2014). Access to Diagnostic Tests and Essential Medicines for Cardiovascular Diseases and Diabetes Care: Cost, Availability and Affordability in the West Region of Cameroon. Published online 2014 Nov 4. doi: 10.1371/journal.pone.0111812.

[13] Johannesson M and Fagerberg B. (1992). A health-economic comparison of diet and drug treatment in obese men with mild hypertension. PMID: 1328366.

[14] Justin B and Andre P ((2011). Chronic non-communicable diseases in Cameroon - burden, determinants and current policies. Global Health Journal, 44.
[15] JV Neel. (1962). Diabetes millitus: genotype redered detrimental by "progress"? Americn journal of Human Genethics.

[16] KonnopkaA., Bödemann M. and König H. (2011). Health burden and costs of obesity and overweight in Germany. The European Journal of Health Economics Vol. 12, No. 4 August, pp. 345-352.

[17] Lewis Landsberg, Louis J., Lawrence J., Valerie Burke, Donald Lloyd-Jones and James Sower, (2013). ObesityRelated Hypertension: Pathogenesis, Cardiovascular Risk, and Treatment. Journal of clinical hypertension. Volume 15, Issue 1, Pages 14-33.

[18] Lindeboom M, Lunborg P and Van Der Klaauw B. (2010). Assessing the impact of obesity on labor market outcomes. Journal of Public Medicine. Elsevier B. V., 20864420.

[19] Manga Simon, Kanjo M, Ngwa W (2017). Challenges with Cervical Cancer Treatment in Cameroon. Obstet Gynecol Cases Rev 2017, 4: 104.

[20] MDG. (2010). Millennium Development Goals, Internet: http://www.planning.gov.mv. Maldives Country Repo: Department of National Planning, Ministry of Finance and Treasury.

[21] National Cancer Institute. (2012). Obesity and Cancer Risk.journal of National cancer institute.

[22] National institute of public health Quebec. (2014) htts://www.ins pq.qc.ca.

[23] Ndi, N. (2010). Treatment for cancer too costly for an average Cameroonian. Vanguard Cameroon.

[24] Ndumbe, P. M. 1998. "Benchmarks" and Health reforms in Cameroon. British Medical Journal.

[25] Nouetchognou, u. S. 2015. The Silent Epidemic: Noncommunicable diseases in Cameroon. Journal of Foretia Foundation.

[26] Obesity, Physical Activity and Diet. (2013). England statistics report.

[27] Price Adi J.. (2011). Cancer care challenges in developing countries. cancer volumn 118 issue 14.

[28] Rigby and James, P. (2003). Waiting for a green light for health? Europe at the crossroads for diet and disease. Obesity task Force Possition Paper, London, NWI2NS.

[29] Runge, C. F. 2007. Economic Consequences of the Obese. Health Affairs journal. Diabetes.; 56 (11): 2668-2672..

[30] SDG. (2010). Sustainable Development Goals. Cameroon. www.un.org.

[31] Sobal, Jeffery, and Albert J. Stunkard. (1989). Socioeconomic Status and Obesity: A Review of the Literature.."Psychological Bulletin, 105.

[32] Surg, W. (1998). Cost-benefit analysis for the treatment of severe obesity. Journal of Public Medicine. Sep; 22 (9): 100817. PMID: 9717430.

[33] Tanya A. N. K., Lantum D. A. and Tanya V. N. 2011. Nutrition and Public Health in Cameroon: Combating the Crisis. Cameroon Academy of Sciences, Yaoundé, Cameroon. 
[34] Wang L. Y. Yang Q., Lowry R. and wester H (2003). Economic Analysis of a School-Based Obesity Prevention Program. Pub med journal DOI: 10.1038/oby.2,178.

[35] WHO. (2012). Facts and Figures of obesity and overweight. www.who.int.

[36] WHO. (2013). Obesity Facts \& Figures. Fack Sheet on Obesity Facts and Figures, $N^{\circ} 311$. www.who.int.
[37] WHO. (2014). obesity facts and figures. www.who.int, 311

[38] World Bank. (2010). Facks and Figures of Overweight and Obesity data.worldbank.org..

[39] Yates J andMurphy C. (2006). A cost benefit analysis of weight management strategies. USA: National Library of Medicine National Institutes of Health. 